\title{
Functional Constipation in the General Population in Cotonou: Prevalence and Associated Socio-Demographic Factors
}

\author{
Jean Sehonou ${ }^{*}$, Aboudou Raïmi Kpossou ${ }^{1}$, Comlan N'dehougbèa Martin Sokpon'1, \\ Hugues Cataria', Colette Azandjeme ${ }^{2}$, Koffi Rodolph Vignon'
}

\footnotetext{
${ }^{1}$ Department of Gastroenterology and Hepatology, National University Hospital Center-Hubert Koutoukou Maga (CNHU-HKM), Cotonou, Benin

${ }^{2}$ Regional Institute of Public Health (IRSP), Ouidah, Benin

Email:^jsehonou@yahoo.fr, kpossou.raimi@yahoo.fr, cathugflo@gmail.com,msokpon@yahoo.fr, colsyaz@yahoo.fr,rkvignon@yahoo.fr
}

\begin{abstract}
How to cite this paper: Sehonou, J., Kpossou, A.R., Sokpon, C.N.M., Cataria, H., Azandjeme, C. and Vignon, K.R. (2018) Functional Constipation in the General Population in Cotonou: Prevalence and Associated Socio-Demographic Factors. Open Journal of Gastroenterology, 8, 306-316.

https://doi.org/10.4236/ojgas.2018.89033
\end{abstract}

Received: August 15, 2018

Accepted: September 23, 2018

Published: September 26, 2018

Copyright ( 2018 by authors and Scientific Research Publishing Inc. This work is licensed under the Creative Commons Attribution International License (CC BY 4.0).

http://creativecommons.org/licenses/by/4.0/

Open Access

\begin{abstract}
Background: Constipation is considered rare in sub-Saharan Africa because of the high fiber content of the local diet. However, certain factors could intervene in this pathology. The purpose of this study was to assess the prevalence of constipation in the general population in Cotonou and to determine the associated socio-demographic factors. Methods: This was a cross-sectional descriptive and analytical study conducted from July to August 2017 in 7 districts of the township of Cotonou, according to a cluster sampling. We included anyone over the age of 15 living in the city of Cotonou for at least 6 months. Constipation was either self-reported or functional (meeting the Rome IV criteria). Results: A total of 1058 participants were included: 574 men (sex ratio of 1.2), mean age of 29 years [range 15 - 92]. Self-reported constipation was noted in 512 patients (48.5\%). It was functional in 256 cases (24.2\%). In the latter category, there was a predominance of women (138, $53.9 \%)$, of secondary education (46.5\%), of self-employed professionals (50.4\%), from the Ouémé-Plateau (41.8\%). Were associated with the occurrence of functional constipation (univariate analysis), age $\geq 60$ years ( $\mathrm{p}=$ $0.049)$, female gender $(\mathrm{p}=0.003)$, and subjects living alone $(166,64.8 \%)$ vs. those living in a relationship $(90,35.2 \%, \mathrm{p}=0.001)$. Conclusion: Constipation was not as rare in Cotonou. It was more common in women, subjects over 60 years old or living alone.
\end{abstract}

\section{Keywords}

Constipation, General Population, Prevalence, Associated Factors, Cotonou 


\section{Introduction}

Constipation is often defined as a symptom of dissatisfaction with defecation due to either uncommon stools (less than 3 stools a week), difficulty exonerating, or both [1]. It can be acute or chronic.

Constipation can sometimes take acute pseudo-surgical forms in rare cases. Most often it is chronic. It can be secondary to muscular or endocrine neurological diseases. Most often it is primitive. Constipation can be self-reported or meet criteria. A more recent definition, that according to the Rome IV criteria is more precise. These criteria are as follows: an onset of symptoms greater than 6 months with the presence of at least two of the following symptoms over the last three months: flare-ups (greater than $25 \%$ of defecations), hard or fragmented stools (greater than $25 \%$ of defecations), an incomplete sensation of evacuation (greater than $25 \%$ of defecations), an anorectal blocking sensation (greater than $25 \%$ of defecations), digital maneuvers (greater than $25 \%$ of defecations) and less than 3 spontaneous evacuations per week (greater than $25 \%$ of defecations) [2].

Its pathogenesis is multifactorial: it involves intrinsic factors (genetic predispositions, low level of parental education, intestinal motility disorders, hormonal imbalances, psychological disorders and depression) [3], and also involves behavioral factors (low fiber consumption, food and drinking water, low level of physical activity, failure to respond to the need for defecation) and environmental factors (life events, drug side effects, or socio-economic factors) [4].

Data on the disease in Africa, however, remain limited and findings remain contradictory. For some, while the Western has an average transit of 70 hours with $100 \mathrm{~g}$ of stool, the average African has a transit of 36 hours on average with a stool weight of $450 \mathrm{~g}$ [5]. For others, constipation is poorly quantified in Africa, but studies in urban hospital settings report its high frequency. We also know its place in traditional medicine which has a therapeutic arsenal based on decoctions and enemas drastic [6].

In Benin, several studies have been conducted on digestive disorders. However, to our knowledge, none has focused on constipation in the general population or more specifically on socio-demographic aspects. This lack of information about the disease in Benin led us to do this study. The objective was to assess the prevalence of constipation in the general population in Cotonou and to determine the associated sociodemographic factors.

\section{Methods}

It was a descriptive and analytical cross-sectional study, with a prospective collection of data over a two-week period from July 28 to August 10, 2017. The study took place in 7 districts of the township of Cotonou, according to a cluster sampling. We included anyone aged at least 15 years old and living in Cotonou for at least 6 months. People who have undergone colon surgery or hospitalization during the inclusion period were not included. Pregnant people and people with mental disabilities were not also in the study. The sampling 
method was a probabilistic method with a 4-stage cluster sampling technique (first degree: borough, second degree: neighborhoods, third degree: dwelling, fourth degree: individuals). In each dwelling, the list of all target subjects is established to allow the selection of a single person. Only one subject is chosen by simple random draw on this list. The verbal consent of the chosen subjects was obtained. The sample size calculated using Schwartz's formula was 784 subjects. We recruited a total of 1058 people.

The dependent variable was constipation. Constipation was either self-reported or functional (meeting the Rome IV criteria as outlined above). Subjects with constipation and warning signs (hematochezia, weight loss, chronic constipation recently aggravated...) were not taken into account in the definition of functional constipation. The independent variables studied were: age, sex, occupation, level of education, ethnicity, marital status, monthly income, patient's residence during the study.

Data collection was done in a direct interview, based on a standardized questionnaire. The questionnaire used in the interview (see Appendix at the end of this manuscript) was designed by us. A test was conducted on the investigators to verify the validity and reliability of the questionnaire. Data capture, processing and analysis were performed using SPSS 21 software. Continuous variables were expressed on average with their standard deviation. Percentages were calculated on categorical variables. Comparisons were made between averages using Student's test, between the proportions using Pearson's Chi Square test or Fisher's exact test. The univariate analysis strategy was used to identify significant associations. The statistical significance level was 5\%.

\section{Results}

\subsection{Characteristics of the Study Population}

Among the 1058 participants included, there were 574 men (54.3\%), i.e. a male predominance with a sex-ratio of 1.2. The average age was 29 years old with extremes of 15 years and 92 years. The other characteristics are presented in Table 1.

\subsection{Prevalence of Constipation}

Among the 1058 participants, self-reported constipation was noted in 512 subjects, i.e. a prevalence of $48.4 \%$.

Functional constipation, defined according to the Rome IV criteria, was noted in 256 participants, i.e. a prevalence of $20.4 \%$.

\subsection{Sociodemographic Factors Associated with Functional Constipation}

As shown in Table 2, among the 256 participants constipated according to the Rome IV criteria, there was a female predominance (138 women or $53.9 \%$ ) with a sex-ratio of 0.85 and a statistically significant relationship between sex and constipation $(\mathrm{p}=0.003)$. 
Table 1. Distribution of respondents by other socio-demographic characteristics (other than sex and age).

\begin{tabular}{|c|c|c|}
\hline & Numbers (N) & Percentage (\%) \\
\hline \multicolumn{3}{|l|}{ Marital status } \\
\hline Single & 626 & 59.2 \\
\hline In a relationship & 369 & 34.9 \\
\hline Divorced & 26 & 2.5 \\
\hline Widower & 37 & 3.5 \\
\hline \multicolumn{3}{|l|}{ Profession } \\
\hline Crafts/traders & 514 & 48.6 \\
\hline Executives/Intellectual & 14 & 1.3 \\
\hline \multicolumn{3}{|l|}{ Professions } \\
\hline Intermediate & 80 & 7.6 \\
\hline \multicolumn{3}{|l|}{ Professions } \\
\hline Pupils/Students & 416 & 39.3 \\
\hline Pensioners & 10 & 0.9 \\
\hline Workers & 17 & 1.6 \\
\hline Unemployed & 7 & 0.7 \\
\hline \multicolumn{3}{|l|}{ Level of study } \\
\hline Not educated & 120 & 11.3 \\
\hline Primary & 239 & 22.6 \\
\hline Secondary & 534 & 50.5 \\
\hline Superior & 165 & 15.6 \\
\hline Total & 1058 & 100 \\
\hline
\end{tabular}

Table 2. Distribution of constipated by sex and average monthly income.

\begin{tabular}{cccccc}
\hline & \multicolumn{2}{c}{ Functional constipation } & \multicolumn{3}{c}{ Univariate analysis } \\
\cline { 2 - 6 } & Yes & No & OR & CI (95\%) & p-value \\
\hline Sex & & & & & \\
Woman & $138(53.9 \%)$ & $346(43.1 \%)$ & 1.54 & $1.16-2.04$ & 0.003 \\
Man & $118(46.1 \%)$ & $456(56.9 \%)$ & 1 & & \\
$\begin{array}{c}\text { Average } \\
\text { monthly }\end{array}$ & & & & & \\
$\begin{array}{c}\text { income in } \\
\text { FCFA }\end{array}$ & 21,569 & 21,494 & - & 17,784 to & 0.985 \\
\hline
\end{tabular}

The most affected age group was 60 years and older (99 cases, 38.7\%) with a statistically significant age-constipation link $(\mathrm{p}=0.049)$. The age distribution is shown in Figure 1.

Sociodemographic factors studied other than age and sex, and their association or non-association with functional constipation was presented in Table 3.

It revealed that there is a statistically significant relationship between marital status and constipation $(\mathrm{p}=0.001)$ : single people were the most affected (54.7\%). 


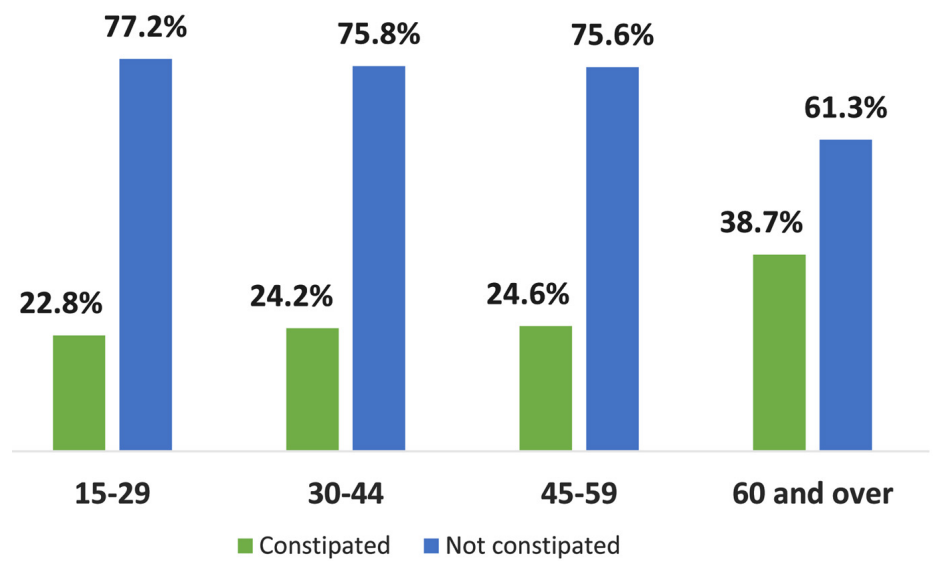

Figure 1. Distribution of constipation according to the Rome IV criteria according to age; $\mathrm{p}=0.049$.

Table 3. Distribution of functional constipation by marital status, level of education and occupation.

\begin{tabular}{|c|c|c|c|c|c|}
\hline & \multicolumn{2}{|c|}{ Functional constipation } & \multicolumn{3}{|c|}{ Univariate analysis } \\
\hline & Yes & No & OR & CI $(95 \%)$ & p-value \\
\hline \multicolumn{6}{|l|}{ Marital status } \\
\hline Single & $140(54.7 \%)$ & $486(60.6 \%)$ & - & - & 0.001 \\
\hline In a relationship & $90(35.2 \%)$ & $279(34.8 \%)$ & & & \\
\hline Divorced & $7(2.7 \%)$ & $19(2.4 \%)$ & & & \\
\hline Widower & $19(7.4 \%)$ & $18(2.2 \%)$ & & & \\
\hline \multicolumn{6}{|l|}{ Profession } \\
\hline Non educated & $38(14.8 \%)$ & $82(10.2 \%)$ & - & - & 0.183 \\
\hline Primary & $60(23.4 \%)$ & $179(22.3 \%)$ & & & \\
\hline Secondary & $119(46.5 \%)$ & $415(51.7 \%)$ & & & \\
\hline Superior & $39(15.2 \%)$ & $126(15.7 \%)$ & & & \\
\hline \multicolumn{6}{|l|}{ Professional status } \\
\hline Crafts/traders & $129(50.4 \%)$ & $385(48 \%)$ & - & - & 0.84 \\
\hline Executives/Intellectual professions & $4(1.4 \%)$ & $10(1.2 \%)$ & & & \\
\hline Intermediate professions & $18(7 \%)$ & $62(7.7 \%)$ & & & \\
\hline Pupils/Students & $100(39.1 \%)$ & $316(39.4 \%)$ & & & \\
\hline Pensioners & $2(0.8 \%)$ & $8(1 \%)$ & & & \\
\hline Workers & $3(1.2 \%)$ & $14(1.7 \%)$ & & & \\
\hline Unemployed & - & $7(0.9 \%)$ & & & \\
\hline
\end{tabular}

Monthly income, level of education and occupation were not statistically associated with constipation (as shown in Table 2 and Table 3).

\section{Discussion}

The prevalence of constipation varies according to the diagnostic criteria used. Based on the Rome IV criteria defining functional constipation, the prevalence 
of constipation in Cotonou was $24.2 \%$. It is relatively high. Comparing this prevalence with those cited in the literature can be difficult, due to the recent update (May 2016) of the Rome criteria. We did not find any studies that used the Rome IV criteria to determine the prevalence of constipation. Our prevalence of constipation noted in Cotonou is close to that of $24 \%$ found in Italy by Cottone C et al. in a prospective study in 2014 (Criteria of Rome II) [7]. On the other hand, it exceeds the $16.7 \%$ rate found by Pare et al. in Canada following a questionnaire survey (Rome I Criteria) [8]. This variability in the prevalence of constipation could be explained not only by different diagnostic criteria but also by the collection techniques used. The prevalence of self-reported constipation we found in Cotonou was $48.4 \%$. This result is above those found by Frexinos in 1998 in France which was 35\% [9], and Haug TT in 2002 in Norway which was $20.2 \%$ [10]. However, it is within the range of $0.7 \%$ to $81 \%$ found by George Peppas et al. according to a survey of 21 studies of constipation in different parts of the world [11]. This variability in prevalence rates could be explained by the subjective nature of this definition of constipation. The perception of constipation varies from one individual to another. The variability in the prevalence of constipation is therefore easily understood.

Regarding the associated factors, there is a statistically significant relationship between age and constipation $(\mathrm{p}=0.049)$, with a peak of the constipated population in the age group of 60 and over. These results are similar to those reported by $\mathrm{Chu} \mathrm{H}$ et al. in China in 2014 [12], and also similar to those of Higgins and Johanson in North America who noted that constipation most often occurred after age of 65 [13]. All authors agree on the relation between high age and constipation. Changes in the enteric nervous system (with decreased normal bowel movements) and large parietal fibrosis observed in the elderly would be responsible for this [14]. In addition, with age, water consumption decreases, the diet is often inappropriate (low fiber content), physical activity decreases and co-morbidities increase, with iatrogenic consequences [4]. Age greater than 65 years is also associated with dentition that is more often incomplete, wearing dentures, and difficulty chewing food, forcing subjects to choose low-fiber foods [4]. All this can explain this increase in the frequency of constipation with age.

The female sex was predominant (53.9\%) with a sex ratio of 0.85 among the constipated. These results are similar to those reported by Miele E et al. in Italy in 2004 [15], and close to 0.89 of Bommelaer et al. in France in 1986 (questionnaire survey) [16]. On the other hand, the female predominance in our study is less important than in the study of Garrigues V et al. in Spain in 2004 (questionnaire survey sent by mail); their sex ratio was 0.45 [17]. There is a difference in the estimates of the sex-ratio. However, the average value remains below 1 in almost all studies. These differences could be explained by a variability in the choice of the diagnostic method. This predominance of women has been attributed to hormonal factors leading to a higher risk of constipation during the luteal phase of the menstrual cycle under the effect of progesterone, and to the effects of delivery on pelvic floor muscles [18]. 
From our study, it was found that there is a statistically significant relation between marital status and constipation ( $\mathrm{p}=0.001)$, singles were the most affected (54.7\%). A study by Perveen I et al. found marital status and constipation to be related, but married people were the most affected [19]. Chang JY et al. had found rather that there was no link between marital status and constipation [20]. These differences in outcomes could be explained in several ways: the diagnostic method used, the technique of collection, and the fact that some singles living in concubinage, their habits could therefore be closer to those of married people. On the other hand, one could assume that single people were more likely to suffer from psychological disorders such as anxiety, depression or that they were more stressed than people living in a relationship. Haug $\mathrm{T}$ reported that these disorders would promote constipation [10]. The mechanisms explaining this association could however not be elucidated.

From our study it appeared that there was no connection between the profession and the occurrence of constipation. We did not find authors in the literature who reported a relation between occupation and constipation.

Similarly, we did not find a link between level of education and constipation. Our results are identical to those reported by Chang JY et al. in the United States [20]; they are contrary to those of Higgins PD and Johanson JF in North America who reported that a low level of education was a risk factor for constipation [14]. These results could be explained by the fact that educated people have easier access to information via the media and the internet. The results we obtained, however, prove that constipation is not necessarily related to the level of study but to other cofactors.

In our study, we found no link between income and constipation. These results are contrary to those reported by Johanson JF in the United States [14], and Schmidt FM and Santos VL [21] in Brazil who noted that a low socio-economic level was a risk factor for constipation. This could be explained by the fact that for people and households with low incomes, food choices are regularly moving towards a diet of low nutritional quality, likely to favor chronic diseases related to insufficiencies of contributions in essential nutrients [22]. These data suggest that the rich would have better sanitation, better nutrition (since they have access to information through the media, books and the internet) or better health in general. It should be noted that the average monthly income per patient appears quite low in our study (21,569 FCFA), compared to the guaranteed minimum wage in Benin which was 40,000 FCFA. This is due to the fact that we mainly included students/pupils and craftsmen/traders, because they were the ones who were mostly available during our survey.

The limits of this study concern essentially some information biases:

- Some respondents did not know their exact date of birth; therefore their age could be biased.

- Some respondents were reluctant to report their income. It is possible that some of the reported revenues are not accurate. 
- The period during which the collection was made corresponded to the long holidays, that is why the age group most represented among the respondents was 15 to 29 years old; this also explains the marital status and level of education of most of them. It is therefore possible that the prevalence of constipation is actually greater than that found in this study.

\section{Conclusion}

Constipation was relatively common in Cotonou. Socio-demographic factors associated with it are high age, female gender, and marital status. Socio-economic factors were of modest importance in this study.

\section{Conflicts of Interest}

The authors declare no conflicts of interest regarding the publication of this paper.

\section{References}

[1] Piche, T., Dapoigny, M., Bouteloup, C., et al. (2007) French Gastroenterology Society: Recommandations pour la pratique clinique dans la prise en charge et le traitement de la constipation chronique de l'adulte. Gastroentérologie Clinique et Biologique, 31, 125-135. https://doi.org/10.1016/S0399-8320(07)89342-0

[2] Vitton, V. Traitement de la constipation de l'adulte. http://www.fmcgastro.org/wp-content/uploads/file/pdf-2017/029_034_Vitton.pdf

[3] Hosseinzadeh, S.T., Poorsaadati, S., Radkani, B. and Forootan, M. (2011) Psychological Disorders in Patients with Chronic Constipation. Gastroenterology and Hepatology from Bed to Bench, 4, 159-163.

[4] Forootan, M., Bagheri, N. and Darvishi, M. (2018) Chronic Constipation: A Review of Literature. Medicine, 97, e10631. https://doi.org/10.1097/MD.0000000000010631

[5] http://www.proktos.com/patients/proctologie-au-quotidien/constipation/transit-etconstipation-normalit\%C3\%A9

[6] Camara, B.M. (1999) La constipation. Médecine d Afrique Noire, 46, 244-247.

[7] Cottone, C., Tosetti, C., Disclafani, G., Ubaldi, E. and Cogliandro, R. (2014) Clinical Features of Constipation in General Practice in Italy. United European Gastroenterology Journal, 2, 232-238. https://doi.org/10.1177/2050640614527283

[8] Pare, P., Ferrazzi, S., Thompson, W.G., Irvine, E.J. and Rance, L. (2001) An Epidemiological Survey of Constipation in Canada: Definitions, Rates, Demographics, and Predictors of Health Care Seeking. The American Journal of Gastroenterology, 96, 3130-3137. https://doi.org/10.1111/j.1572-0241.2001.05259.x

[9] Frexinos, J., Denis, P., Allemand, H., Allouche, S., Los, F. and Bonnelye, G. (1998) Descriptive Study of Digestive Functional Symptoms in the French General Population. Gastroentérologie Clinique et Biologique, 22, 785-791.

[10] Haug, T.T., Mykletun, A. and Dahl, A.A. (2002) Are Anxiety and Depression Related to Gastrointestinal Symptoms in the General Population? Scandinavian Journal of Gastroenterology, 37, 294-298. https://doi.org/10.1080/003655202317284192

[11] Peppas, G., Alexiou, V.G., Mourtzoukou, E. and Falagas, M.E. (2008) Epidemiology of Constipation in Europe and Oceania: A Systematic Review. BMC Gastroenterology, 8, 1-7. https://doi.org/10.1186/1471-230X-8-5 
[12] Chu, H., Zhong, L., Li, H., Zhang, X., Zhang, J. and Hou, X. (2014) Epidemiology Characteristics of Constipation for General Population, Pediatric Population, and Elderly Population in China. Gastroenterology Research and Practice, 2014, 1-11. https://doi.org/10.1155/2014/532734

[13] Higgins, P.D. and Johanson, J.F. (2004) Epidemiology of Constipation in North America: A Systematic Review. The American Journal of Gastroenterology, 99, 750-759. https://doi.org/10.1111/j.1572-0241.2004.04114.x

[14] Ndam, A.N., Melchior, C., Gourcerol, G., Leroi, A.M. and Ducrotté, P. (2017) Constipation Fonctionnelle Chronique de L'Adulte: Quelles Nouveautés? Hépato-Gastro \& Oncologie Digestive, 24, 667-677.

[15] Miele, E., Simeone, D., Marino, A., et al. (2004) Functional Gastrointestinal Disorders in Children: An Italian Prospective Survey. Pediatrics, 114, 73-78.

https://doi.org/10.1542/peds.114.1.73

[16] Bommelaer, G., Rouch, M., Dapoigny, M., et al. (1986) Épidémiologie des troubles fonctionnels intestinaux chez une population apparemment en bonne santé. Gastroentérologie Clinique et Biologique, 10, 7-12.

[17] Garrigues, V., Galvez, C., Ortiz, V., Ponce, M., Nos, P. and Ponce, J. (2004) Prevalence of Constipation: Agreement among Several Criteria and Evaluation of the Diagnostic Accuracy of Qualifying Symptoms and Self-Reported Definition in a Population-Based Survey in Spain. American Journal of Epidemiology, 159, 520-526. https://doi.org/10.1093/aje/kwh072

[18] Chiarelli, P., Brown, W. and McElduff, P. (2000) Constipation in Australian Women: Prevalence and Associated Factors. International Urogynecology Journal, 11, 71-78. https://doi.org/10.1007/s001920050073

[19] Perveen, I., Rahman, M.M., Saha, M., Parvin, R. and Chowdhury, M. (2015) Functional Constipation-Prevalence and Life Style Factors in a District of Bangladesh. Mymensingh Medical Journal, 24, 295-304.

[20] Chang, J.Y., Locke, G.R., Schleck, C.D., Zinsmeister, A.R. and Talley, N.J. (2007) Risk Factors for Chronic Constipation and a Possible Role of Analgesics. Neurogastroenterology \& Motility, 19, 905-911. https://doi.org/10.1111/j.1365-2982.2007.00974.x

[21] Schmidt, F.M., de Gouveia Santos, V.L., de Cássia Domansky, R. and Neves, J.M. (2016) Constipation: Prevalence and Associated Factors in Adults Living in Londrina, Southern Brazil. Gastroenterology Nursing, 39, 204-211. https://doi.org/10.1097/SGA.0000000000000224

[22] Bernard, B. (2005) Bien se nourrir sans trop dépenser: Savoir choisir ses aliments. Combien coûte une alimentation équilibrée? Alimentation et précarité, 31, 3. 


\section{Appendix}

Constipation and associated factors in cotonou general population

Survey Sheet

Check the correct answer and specify the constants

Fill date

\section{Criteria of non-inclusion}

Do not include if the patient answers Yes to any of these questions:

Age $<15$ years: Yes $\square$ No $\square$; Living in Cotonou for less than 6 months: Yes No $\square$; Current pregnancy: Yes $\square$ No $\square$; Mental disabilities: Yes $\square$ No $\square$; Current hospitalization: Yes $\square$ No $\square$; History of colonic surgery: Yes $\square$ No $\square$

\section{General Information}

Investigation Sheet No

Initials and surnames (first two letters of each).....

Phone.

Neighborhoods.

\section{Sociodemographic data}

Age........ Sex: Man $\square$ Woman $\square$

Marital status: Single $\square$ In a relationship $\square$ Divorced $\square$ Widower $\square$

Profession: Trader $\square$ Teacher $\square$ Artisan $\square$ Health worker $\square$ Household

Pupils $\square$ Student $\square$ Engineer $\square$ Accountant $\square$ Secretary $\square$ Religious

Other.

Level of study: Not educated $\square$ Primary $\square$ Secondary $\square$ Superior $\square$

Departement of origin: Littoral $\square$ Atlantique $\square$ Atacora $\square$ Donga $\square$ Couffo $\square$ Mono $\square$ Zou $\square$ Collines $\square$ Ouémé $\square$ Plateau $\square$ Alibori $\square$ Borgou $\square$

Approximate monthly income (FCFA)

\section{Alarm signs}

Alarm sign: Yes $\square$ No $\square$; If yes, specify: hematochezia $\square$ weight loss chronic constipation recently aggravated $\square$ Anemia $\square$ Personal or family history of colon or rectal cancer $\square$

\section{Diagnosis retained}

By the participant: Do you feel constipated? Yes $\square$ No $\square$

By the practitioner: Constipation: Yes $\square$ No $\square$

Functional constipation according to the Rome IV criteria: Yes $\square$ No $\square$

[Rome IV criteria for constipation: an onset of symptoms greater than 6 months with the presence of at least two of the following symptoms over the last three months: flare-ups (greater than $25 \%$ of defecations), hard or fragmented stools (greater than $25 \%$ of defecations), an incomplete sensation of evacuation (greater than $25 \%$ of defecations), an anorectal blocking sensation (greater than $25 \%$ of defecations), digital maneuvers (greater than $25 \%$ of defecations) and less than 3 spontaneous evacuations per week (greater than $25 \%$ of defecations)].

Irritable bowel syndrome with constipation: Yes $\square$ No $\square$

[Rome IV criteria for irritable bowel syndrome: Chronic abdominal pain or 
discomfort occurring one day per week in the last 3 months associated with the following 2 points: 1) In relation with the defecation, 2) Associated with a change in the frequency or appearance of stool. The symptoms must have started for at least 6 months]. 